\title{
Role of leptin and visfatin in infertility in obese and non obese women
}

\author{
Hussein Mohamed Hussein, Mahmoud Raafat Abdel Fadeil, Abdou Saeed Ait-allah
}

\begin{abstract}
Infertility considered a big health problem with increasing prevalence, having several causes, some of these causes refer to adipose tissue abnormalities. Many substances secreted from white adipose tissue like leptin, visfatin may have a role in several cases in infertility in women Objective:to answer questions concerned with the relation between lepin, visfatin and omen's infertility through analysis of data from previous studies.
\end{abstract}

Thwe strategy of this systematic review will be based on raising some research questions that give an idea about the relationship between leptin and visfatin level and women infertility.

the research questions

1-Is there a relationship between obesity and infertility in women?

2-Is there a relationship between obesity and leptin and visfatin level ?

3 - Is there a relationship between leptin and visfatin level and infertility in women ? 4-Is there a difference in leptin, visfatin level between obese and non obese infertile women?

5-How does leptin, visfatin affect women's fertility?

Keywords: leptin ,visfatin ,obesity, infertility

\section{Introduction}

The fertility of a couple is defined as their ability to obtain a pregnancy. In humans, fertilizability (monthly probability of initiating a pregnancy) is difficult to estimate but is thought to be about 20 to $30 \%$. The 12 -month rate of infertility (absence of pregnancy despite regular unprotected sexual intercourse) is estimated as $9 \%$ worldwide, and among these couples, $56 \%$ consult for this reason [1].

Adipose tissue is dynamically involved in cell function regulation through a complex network of endocrine (signals travel through the circulatory system to reach all parts of the body), paracrine (signals sent Visfatin is a $52-\mathrm{kDa}$ protein 1 , is active as a dimer, with each monomer containing 491 amino acids in humans. This has been proved by the fact that only to cells in the vicinity of the cell station), and autocrine (only affecting cells that are the same type) signals that influence the response of many tissues, including hypothalamus, pancreas, liver, skeletal muscle, kidneys, endothelium, and the immune system, among others. This secretory nature has prompted the view of white adipose tissue as an extremely active endocrine tissue [2].

The most significant roles of leptin include regulation of energy homeostasis, neuroendocrine function, and metabolism. Other effects of leptin involving regulation of immune function [3].

visfatin(PBEF/Nampt)has two activities at the interface of the dimeric protein, suggesting that dimerization is essential for the catalytic activity of the enzyme[4]. 


\section{Discussion}

\section{1-Is there a relation between obesity and infertility in women?} About six studies that met the inclusion criteria were found addressing this issue during the study period, and were considered to be eligible.

All these studies prove that there is a relationship between obesity and infertility in women, obesity has a negative effect on women's fertility. 1- weight loss, is associated with a significant improvement in pregnancy rates and live births in a group of obese women undergoing fertility treatment[5].

2-Adolescent obesity is associated with lifetime nulliparity and nulligravidity in midlife U.S. women[6]. 3-Various measures of overall and central adiposity were associated with decreased fertility among pregnancy planners[7].

4- overweight/obese women with PCOS are at an increased risk for sonographic view of polycystic ovaries.

5- Weight loss improves live birth rates in overweight patients with infertility[9].

6-Female obesity impairs the reproductive outcome of ovum donation probably as a result of reduced uterine receptivity[10].

Second question

2-Is there a Relation between leptin and visfatin level and obesity ? About fourteen studies that met the inclusion criteria were considered to be eligible.

About relation between leptin and visfatin level and obesity ,11 studies prove that there is a positive relation between leptin and visfatin level and obesity, $\mathbf{3}$ studies prove that there is no relation between leptin and vifatin level and obesity .

1-Positive correlations between serum concentrations of visfatin and insulin in the obese group were found[11]. 2- New role of visfatin in inflammation reflected in PBMCs, in the context of obesity[12].

3- Increased adipocytokine expression correlates with BMI[13].

4- Visfatin in obese subjects, which did not correlate with the majority of anthropometric parameters with the exception of WHR (negative correlation)[14].

5- visfatin increase in obesity together with its positive correlation to HOMA might be suggestive of a role in glucose homeostasis[15].

6- In a homogeneous cohort of morbidly obese women, our findings show that visfatin has a strong relationship with proinflammatoryfactors in severe obesity[16].

7- Elevated serum leptin, particularly in obese individuals, should be taken as a warning sign of energy imbalance [17].

8- Obese subjects were more likely to have higher levels of inflammatory and insulin resistance adipocytokines compared to non-obese subjects[18]. 9- The range of adipokines significantly correlated with anthropometric parameters and was found to differ substantially between males and females[19]. 10- The metabolically obese phenotype is characterized by altered adipokine and inflammatory profiles [20]. 11- Leptin concentrations are positively correlated with BMI [21].

12- No correlation was detected between serum visfatin levels and obesity and metabolic parameters [22]. 13- Normal-weight women with AO have normal adiponectin and visfatin levels[23].

14- There were no differences in serum levels of visfatin in comparison to normal weight women[24]. 
Third

question:

Is there a Relation between leptin and visfatin level and infertility in women?

About four studies that met the inclusion criteria were considered to be eligible..

1-A significant difference in serum leptin levels between unexplained infertile and fertile women suggests that this cytokine may be involved in pathophysiology of unexplained infertility[25].

2- Overweight accompanied by hyperleptinemia is associated with infertility in females[26].

3- Obesity is associated with infertility in men and women. Sex hormonal imbalance may also be associated BMI and serum leptin in infertility[27].

4- High leptin level of follicular fluid is one of the main factors involved in infertility[28].

Fourth

4- Is there a difference between leptin and visfatin level between obese and non obese infertile women?

About four studies that met the inclusion criteria were considered to be eligible.

1-Serum visfatin levels were similar in patients with PCOS and controlgroup, Visfatin levels were higher in normal weight PCOS when. compared with obese PCOS, but it did not reach statistical significance[29].

2- Obesity is per se associated with increased adipose expression and plasma levels of leptin, lower expression of adiponectin, and marginally elevated expression of IL-6, but PCOS does not appear to have an independent effect on the adipose expression of leptin, adiponectin, and IL-6 or the circulating adipocytokines[30].

3-While the expression of visfatin and resistin may be upregulated in women with PCOS, it is not translated at serum level, there were no statistically significant differences in serum resistin and visfatin levels between PCOS and control

[31].

groups

4- Increased likelihood of metabolic and dyslipidemic manifestations in obese compared to non-obese PCOS patients, while no significant difference was noted in visfatin and resistin levels among PCOS patients in terms of co-morbid obesity and in comparison to controls[32]. Fifth question : 5-How does leptin and visfatin affect women's fertility?

About eight studies that met the inclusion criteria were considered to be eligible.

1-Hypoleptinemia contributes significantly to the reproductive, neuroendocrine, and bone abnormalities associated with HA[33]. 2- Elevated leptin levels are detected in women with PCOS compared with non-PCOS controls[34]. 3-levels of peritoneal-fluid leptin did not correlate with different stage of endometriosis. However, they correlated with body mass index[35]. 4- Peritoneal leptin plays important roles in the pathogenesis of infertility in the early stage of endometriosis[36]. 5 - leptin and its receptor are induced in ovarian endometriomas, and that the leptin/ObR system regulates adiponectin gene expression in endometriotic cells[37]. 6- Infertility among women with PCOS was not a consequence of changes in leptin concentrations[38]. 7- An increased leptin level among women with PCOS that positively associated with BMI and LH[39].

8- positive interactive effects were found between PCOS status obesity status and leptin and PCOS, they may contribute to the development of PCOS[40]. 


\section{CONCLUSION}

1) Regarding the relationship between obesity and infertility in women. There is a clear relation between obesity and infertility in women, obesity has a negative effect on women's fertility. obesity affect women's fertility by increase incidence of PCO and decrease uterine receptivity, decrease outcomes after ART, weight loss improve women's fertility. 2) Regarding the relationship between obesity and leptin and visfatin level.

There is a relation between level of these two adipokines and obesity.

There is a positive relation between level of leptin and obesity, leptin level increase with obesity.

Visfatin level increase with obesity especially when associated with insulin resistance or DM. 3) Regarding the relation between leptin, visfatin level and infertility in women.

There is a clear positive relationship between level of leptin and visfatin level and infertility in women. 4) Regarding the difference in leptin ,visfatin level between obese and nonobese infertile women. There is no significant difference between leptin and visfatin level between obese and non-obese infertile women.

5) Regarding the mechanism by which leptin and visfatin affect women's fertility.

Normal leptin level is needed for normal reproductive function in women,

impaired leptin level is associated with increase incidence of PCO and endometriosis which reduce fertility in women.

Hypo/hyper leptenemia increase incidence of women's infertility, hyperleptinemia in PCOS women appears to be due to the positive correlation between serum leptin, BMI, and insulin, hypoleptinemia contributes significantly to the reproductive, neuroendocrine abnormalities associated with HA. High visfatin level increase incidence of women's infertility, visfatin level increase in PCO when associated with IR or DM.

\section{References}

1. Boivin, J., Bunting, L., Collins, J. A., \& Nygren, K. G. (2007). International estimates of infertility prevalence and treatment-seeking: potential need and demand for infertility medical care. Human reproduction, 22(6), 15061512.

2.Saely, C. H., Geiger, K., \& Drexel, H. (2012). Brown versus white adipose tissue: a mini-review. Gerontology, 58(1), 15-23.

3.Chan, J. L., Bullen, J., Stoyneva, V., DePaoli, A. M., Addy, C., \& Mantzoros, C. S. (2005). Recombinant methionyl human leptin administration to achieve high physiologic or pharmacologic leptin levels does not alter circulating inflammatory marker levels in humans with leptin sufficiency or excess. The Journal of Clinical Endocrinology \& Metabolism, 90(3),

1618-1624.

4-Wang, T., Zhang, X., Bheda, P., Revollo, J. R., Imai, S. I., \& Wolberger, C. (2006). Structure of Nampt/PBEF/visfatin, a mammalian NAD+ biosynthetic enzyme. Nature structural \& molecular biology, 13(7),

661.

5- Polotsky, A. J., Hailpern, S. M.,

Skurnick, J. H., Lo, J. C., Sternfeld, B., \& Santoro, N. (2010). Association of adolescent obesity and lifetime nulliparity-The Study of Women's Health Across the Nation (SWAN). Fertility and sterility, 93(6), 2004-2011.

6-Bellver, J., Pellicer, A., García-Velasco, J. A., Ballesteros, A., Remohí, J., \& Meseguer, M. (2013). Obesity reduces uterine receptivity: clinical experience from 9,587 first cycles of ovum donation 
with normal weight donors. Fertility and sterility, 100(4), 1050-1058. 7- Sim, K. A., Dezarnaulds, G. M., Denyer, G. S., Skilton, M. R., \& Caterson, I. D. (2014). Weight loss improves reproductive outcomes in obese women undergoing fertility treatment: a randomized controlled trial. Clinical obesity, 4(2), 61-68. 8- Kort, J. D., Winget, C., Kim, S. H., \& Lathi, R. B. (2014). A retrospective cohort study to evaluate the impact of meaningful weight loss on fertility outcomes in an overweight population with infertility. Fertility and sterility, 101(5), 1400-1403.

9- Esmaeilzadeh, S., Andarieh, M. G., Ghadimi, R., \& Delavar, M. A. (2015). Body mass index and gonadotropin hormones (LH \& FSH) associate with clinical symptoms among women with polycystic ovary syndrome. Global journal of health science, 7(2), 101. 10- McKinnon, C. J., Hatch, E. E., Rothman, K. J., Mikkelsen, E. M., Wesselink, A. K., Hahn, K. A., \& Wise, L. A. (2016). Body mass index, physical activity and fecundability in a North American preconception cohort study. Fertility and sterility, 106(2), 451459.

11-Zahorska-Markiewicz, B., OlszaneckaGlinianowicz, M., Janowska, J., Kocełak, P., Semik-Grabarczyk, E., Holecki, M., ... \& Skorupa, A. (2007). Serum concentration of visfatin in obese women. Metabolism, 56(8), 1131-1134. 12- Samara, A., Pfister, M., Marie, B., \& Visvikis-Siest, S. (2008). Visfatin, low-grade inflammation and body mass index endocrinology, 69(4),

(BMI). Clinical 13 Vardhana, P. A., Dicken, C., Tortoriello, D. V., Chu, M., Carmina, E., \& Lobo, R.A. (2009). Increasing adiposity in normal ovulatory women affects adipocytokine expression in subcutaneous and visceral abdominal fat. International Journal of Gynecology \& Obstetrics, 104(2), 121-124. 14- Kamińska, A., Kopczyńska, E., Bronisz, A., Żmudzińska, M., Bieliński, M., Borkowska, A., ... \& Junik, R. (2010). An evaluation of visfatin levels in obese subjects. Endokrynologia Polska, 61(2), 169-173.

15- Reda, R., Shehab, A., Soliman, D., Gabr, A., \& Abbass, A. (2011). Serum visfatin levels in a group of Egyptian obese individuals. The Egyptian journal of immunology, 18(1), 25-32. 16- Terra, X., Auguet, T., Quesada, I., Aguilar, C., Luna, A. M., Hernández, M., ... \& Pellitero, S. (2012). Increased levels and adipose tissue expression of visfatin in morbidly obese women: the relationship with pro-inflammatory cytokines. Clinical endocrinology, 77(5), 691-698.

17- Carmo Martins, M., Faleiro, L. L., \& Fonseca, A. (2012). Relationship between leptin and body mass and metabolic syndrome in an adult population. Revista Portuguesa de Cardiologia (English Edition), 31(11), 711-719.

18- Derosa, G., Fogari, E., D'Angelo, A., Bianchi, L., Bonaventura, A., Romano, D., \& Maffioli, P. (2013). Adipocytokine levels in obese and non-obese subjects: an observational study. Inflammation, 36(4), 914-920.

19- Bienertová-Vašků, J., Novák, J., Zlámal, F., Forejt, M., Havlenová, S., Jackowská, A., ... \& Vašků, A. (2014). The prediction role of indexes of circulating adipokines for common anthropometric and nutritional characteristics of obesity in the obese Central European population. Eating behaviors, 15(2), 244-251.

20- Indulekha, K., Surendar, J., Anjana, R. M., Geetha, L., Gokulakrishnan, K., Pradeepa, R., \& Mohan, V. (2015). Metabolic obesity, adipocytokines, and inflammatory markers in Asian Indians-CURES124. Diabetes technology \& therapeutics, 17(2), 134-141.

21- Luo, Q., Li, N., Abulikem, S., \& Yao, X. (2016). 16-02 ASSOCIATION OF SERUM CONCENTRATIONS OF LEPTIN WITH OBESITY AMONG UYGUR POPULATION IN. Journal of hypertension, 34, e218.

22- Ersoy, C., Sadikoglu, G., Orhan, H., Guclu, M., Sarandol, E., Akgun, M. D., ... \& Imamoglu, S. (2010). Body fat distribution has no effect on serum visfatin levels in 
healthy female subjects. Cytokine, 49(3), 275-278.

23- Miazgowski, T., Major-Goluch, A., \& Safranow, K. (2012). Selected adipokines and metabolic profiles in normal-weight women with abdominal obesity. Pol Arch Med Wewn, 122(9), 406-412. 24- Saboori, S., Hosseinzadeh-Attar, M. J., Hosseini, M., Mirzaei, K., \& Ahmadivand, Z. (2015). The comparison of serum vaspin and visfatin concentrations in obese and normal weight women. Diabetes \& Metabolic Syndrome: Clinical Research \& Reviews, 9(4), 320-323.

25- Demir, B., Guven, S., Guven, E. S. G., Atamer, Y., Gunalp, G. S., \& Gul, T. (2007). Serum leptin level in women with unexplained infertility. Journal of reproductive immunology, 75(2), 145-149.

26- Shafi, R., \& Afzal, M. N. (2008). Status of serum leptin levels in females with infertility. Saudi medical journal, 29(10), 1419-1422.

27- Farooq, R., Lutfullah, S., \& Ahmed, M. (2014). Serum leptin levels in obese infertile men and women. Pakistan journal of pharmaceutical sciences, 27(1).

28-Kamyabi, Z., \& Gholamalizade, T. (2015). A comparative study of serum and follicular fluid leptin concentrations among explained infertile, unexplained infertile and fertile women. International journal of fertility \& sterility, 9(2), 150.

29- Nilgün Güdücü, Herman İşçi, Uzay Grmüş, Alin Başgül Yiğiter \& Ilkkan Dünder. (2012 ).Serum visfatin levels in women with polycystic ovary syndrome. Gynecological Endocrinology, 28(8): 619623.

30- Svendsen, P. F., Christiansen, M., Hedley, P. L., Nilas, L., Pedersen, S. B., \& Madsbad, S. (2012). Adipose expression of adipocytokines in women with polycystic ovary syndrome. Fertility and sterility, 98(1),

235-241.

31- Farshchian, F., Tehrani, F. R., Amirrasouli, H., Pour, H. R., Hedayati, M., Kazerouni, F., \& Soltani, A. (2014). Visfatin and resistin serum levels in normal-weight and obese women with polycystic ovary syndrome. International journal of endocrinology and metabolism, 12(3).

32- Gul, O. O., Cander, S., Gul, B., Açıkgoz, E., Sarandol, E., \& Ersoy, C. (2015). Evaluation of insulin resistance and plasma levels for visfatin and resistin in obese and non-obese patients with polycystic ovary syndrome. European cytokine network, 26(4), 73-78.

33- Chou, S. H., Chamberland, J. P., Liu, X., Matarese, G., Gao, C., Stefanakis, R., ... \& Mantzoros, C. S. (2011). Leptin is an effective treatment for hypothalamic amenorrhea. Proceedings of the National Academy of Sciences, 108(16), 65856590.

34-Zheng, S. H., Du, D. F., \& Li, X. L. (2017). Leptin Levels in Women with Polycystic Ovary Syndrome: A Systematic Review and a Meta-Analysis. Reproductive Sciences, 24(5),

656-670.

35- Tao, Y., Zhang, Q., Huang, W., Zhu, H., Zhang, D., \& Luo, W. (2011). The Peritoneal Leptin, MCP-1 and TNF- $\alpha$ in the Pathogenesis of Endometriosis-Associated

Infertility. American Journal of Reproductive Immunology, 65(4), 403406.

36- Barcz, E., Milewski, Ł., Radomski, D., Dziunycz, P., Kamiński, P., Roszkowski, P. I., \& Malejczyk, J. (2008). A relationship between increased peritoneal leptin levels and infertility in endometriosis. Gynecological

Endocrinology, 24(9), 526-530.

37- Choi, Y. S., Oh, H. K., \& Choi, J. H. (2013). Expression of adiponectin, leptin, and their receptors in ovarian endometrioma. Fertility and sterility, 100(1), 135-141. 38- Dayer, D., Nikbakht, R., \& Elyaderani, M. K. (2013). Comparison of leptin concentrations between infertile women with polycystic ovary syndrome and fertile women. Iranian journal of reproductive medicine, 11(12), 1033. 39-Jalilian, N., Haghnazari, L., \& Rasolinia, S. (2016). Leptin and body 
SOHAG MEDICAL JOURNAL Role of leptin and visfatin in infertility in obese

mass index in polycystic ovary syndrome. Indian journal of endocrinology and metabolism, 20(3), 324. 40- Behboudi-Gandevani, S., Tehrani, F. R., Yarandi, R. B., Noroozzadeh, M.,
Hedayati, M., \& Azizi, F. (2017). The association between polycystic ovary syndrome, obesity, and the serum concentration of adipokines. Journal of Endocrinological Investigation, 1-8. 